\title{
PREHISTORIC TOMBS NEAR ZEBBUG, MALTA
}

\section{(Plates I-III)}

\section{(i) The Tombs and Their Contents}

IN September, 1947, whilst digging trenches for the laying of the foundations of a building in the field known as 'ta Trapna iz-Zghira', in the parish of Zebbug (Ref 394228 on the standard 2-inch map of Malta), five early tombs were discovered. The workmen, not appreciating the importance of the discovery, cut a trench 2 feet wide through the middle of two of these burials, thus partially destroying the deposit. Further destruction was prevented by Mr. Ian Small, Civil Engineer of H.M. Dockyard, who stopped the work and reported the discovery to the Museum; and on inspection of the site it immediately became apparent that we were dealing with tombs of a type hitherto unrecorded. The excavation of these remains was conducted with the fullest care to secure adequate records and ensure the recovery of all the archaeological material.

The tombs were five in number, irregularly disposed within an area of 50 sq. yards (Fig. 1). They all exhibited more or less the same features. Each tomb consisted of a saucer-shaped cavity roughly cut in the rock-bed, which at this point is the soft, white, Middle Globigerina Limestone and which underlies about $2 \mathrm{ft}$. of field soil. The diameter of the tombs averaged about $6 \mathrm{ft}$., and they attained a depth of about $2 \mathrm{ft}$. at the centre. A single layer of flat, roughly chipped slabs, derived from the local rock-bed, was used to pave the tomb floor. These slabs, about 4 in. in thickness and 10 in. in width, varied in length from 6 in. to $2 \mathrm{ft}$. 3 in. Overlying the slabs there was a layer of marl, about 6 in. in thickness, in which were embedded human skeletal remains, mostly: in a fragmentary state and in utter disorder.

Intimately associated with the human remains were numerous fragments of pottery, flint implements, and personal ornaments of sea-shell and bone. The whole layer was profusely impregnated with red ochre. Overlying this was a layer consisting almost exclusively of stone chippings, which was about 10 inches deep. The rest of the deposit, $2 \mathrm{ft}$. $1 \mathrm{o}$ in. in thickness, consisted of ordinary red field soil. A thin layer of angular and rounded stones divided this layer at a depth of $\mathrm{i} f \mathrm{ft} .6 \mathrm{in}$. from the surface; below these stones the earth was hard and compact, but above them it was soft and loose.

\section{Tomb No. I}

Somewhat elliptical in shape, measuring $7 \mathrm{ft} .6 \mathrm{in}$. in maximum length, $5 \mathrm{ft} .9$ in. in maximum breadth and I ft. 6 in. in depth. It was cut through by a modern trench, $2 \mathrm{ft} .3$ in. wide. Only three paving slabs were found in a good state of preservation, the largest of which measured $2 \mathrm{ft} .3$ in. in length and an average of 9 in. in breadth; the rest were in an advanced state of disintegration owing to the softness of the rock of which they were made. Orientation of the major axis of the tomb, NNW. Fig. 2, no. 1, and Pl. I, $a$ and $b$. 
The following objects were recovered from the burial layer:

(a) Pottery:

(1) Small cup with large oval strap-handle and omphalos base. Decorated with incised lines. Complete. Ht. $2 \frac{1}{2}$ in., max. d. $2 \frac{7}{8}$ in., mouth d. $2 \frac{1}{2}$ in. Fig. 5 , no. 3, and Pl. II, a, no. I.

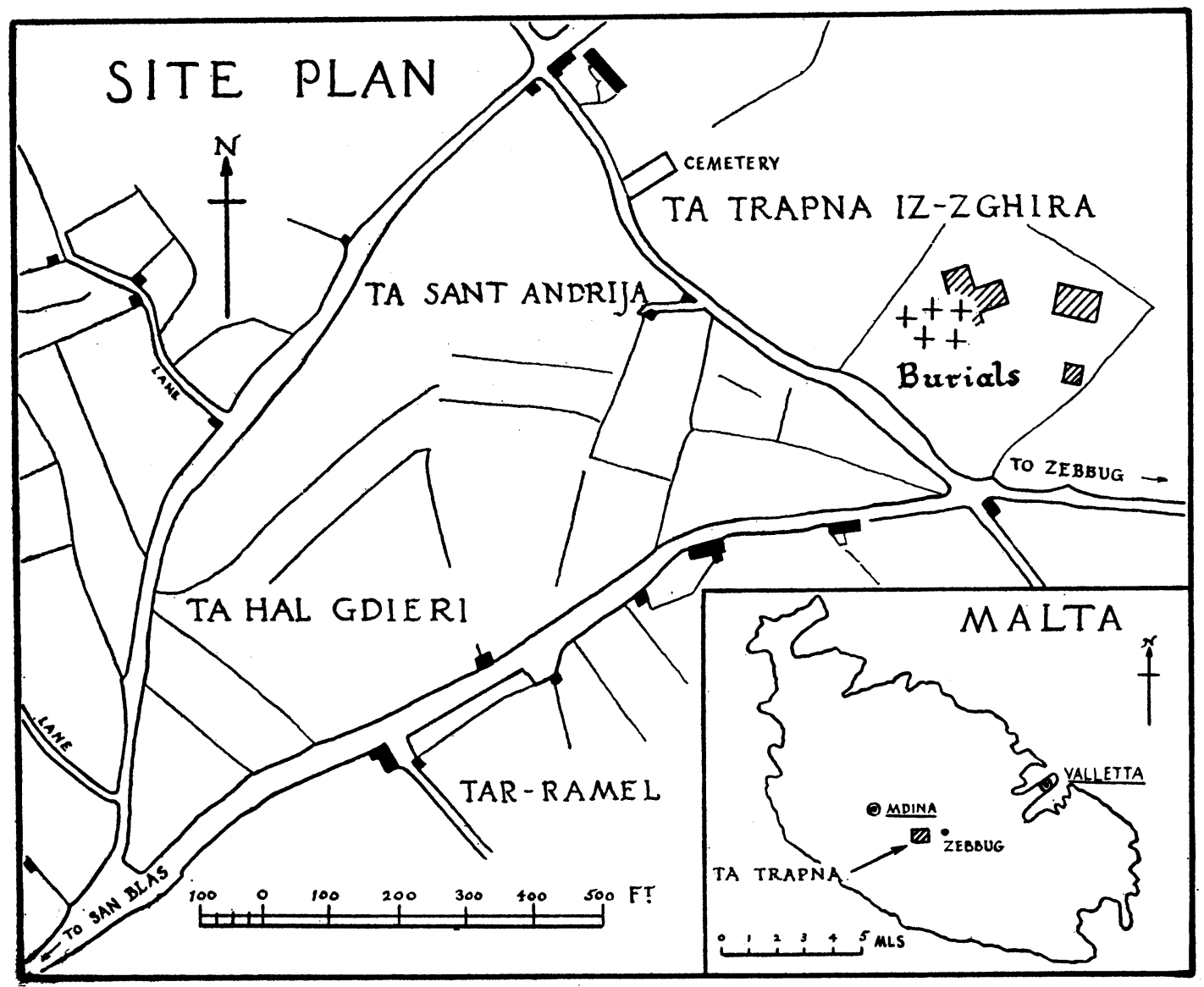

FIG. I.

(2) Portion of a jar with flat base and inverted tronco-conic body. One horizontallypierced lug-handle on preserved portion of shoulder. Neck missing. Incised decoration. Reconstructed. Max. d. $7 \frac{1}{2}$ in. approx. Fig. 4, no. 3, and Pl. II, a, no. 2 .

(3) Portion of the body of a similar jar with incised decoration. Reconstructed. Max. d. $4 \frac{3}{4}$ in. approx. Fig. 4 , no. 4 , and Pl. II, a, no. 3.

(4) Large portion of the shoulder and part of the neck of a similar jar. Two opposed horizontally-pierced lug-handles on the shoulder. Incised decoration. 


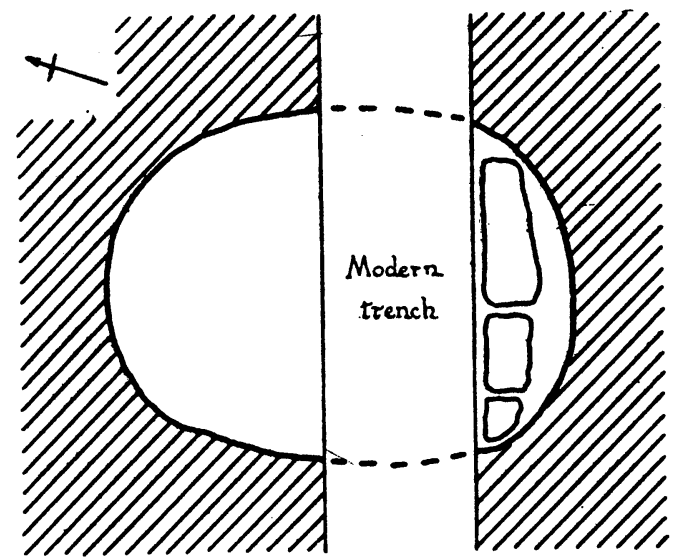

$1 a$

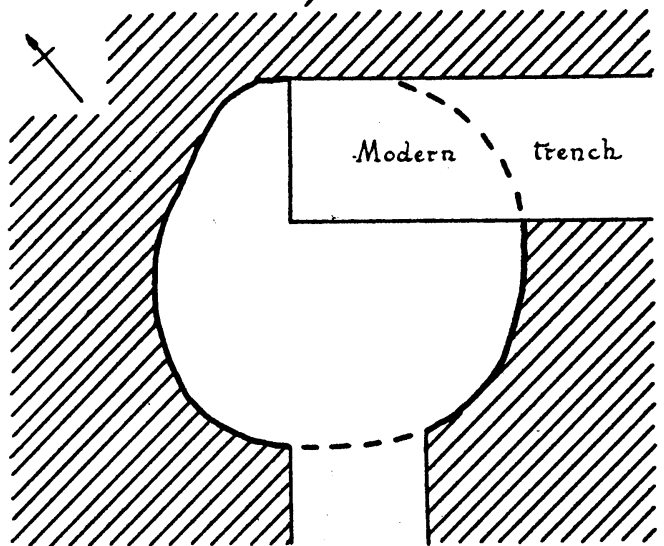

$2 a$

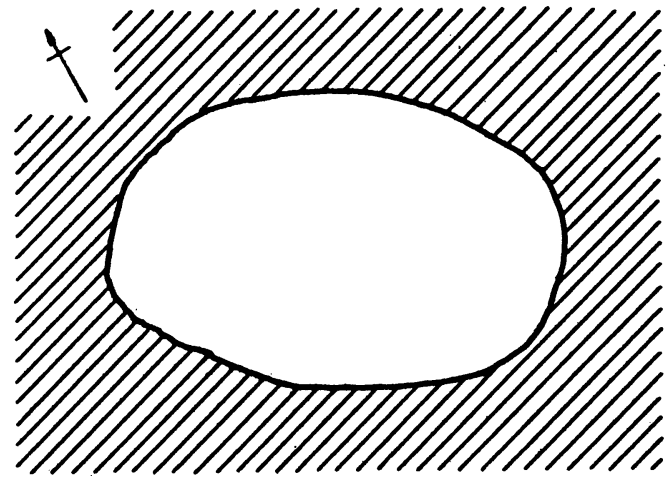

3 a

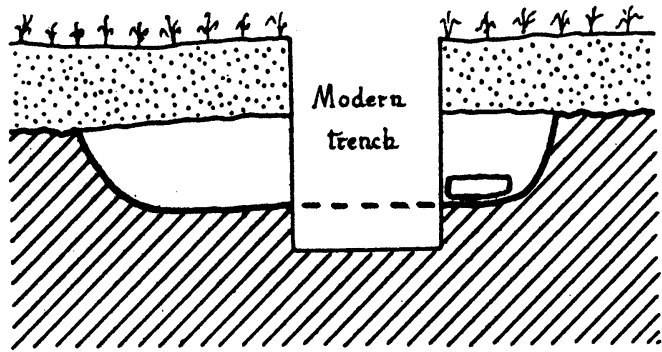

$1 \mathbf{b}$

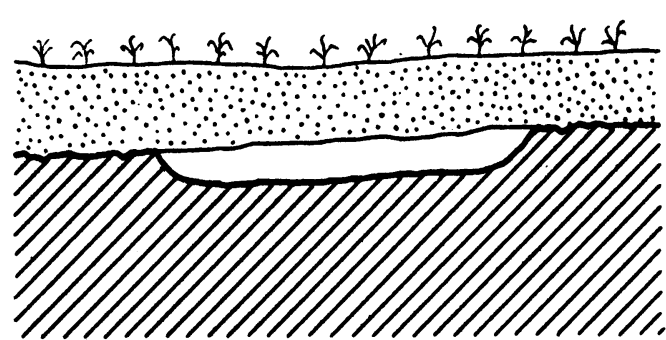

$2 \mathrm{~b}$

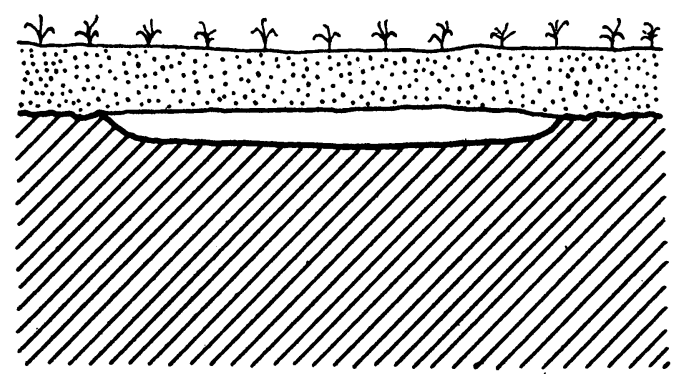

$3 \mathbf{b}$

\section{$10 \quad 1 \quad 2 \quad 3 \quad 4 \quad 5 \quad 6 \quad 7 \quad 8 \quad 910$ Feet.}

FIG. 2. 
(5) Four large fragments of the bell-shaped necks of similar jars, all decorated with knobs and incised lines. Mouth d. $3 \frac{1}{4}, 2 \frac{3}{4}, 3 \frac{1}{4}$, and $2 \frac{3}{8}$ in. respectively.

(6) Portion of a deep, necked bowl decorated with a number of broad, shallow, cutout bands. Restored. Mouth d. $6 \frac{1}{4}$ in. Fig. 4, no. 1 .

Besides these, a considerable quantity of sherds, mostly of jars like (2)-(5), or of a deep bowl like (6), were recovered. All bore an incised decoration.

(b) Other finds:

Flint. One small blade of black flint with triangular section, carefully retouched along both edges. Both ends of the blade have been neatly snapped off. Length $1 \frac{1}{4}$ in., breadth $\frac{5}{8}$ in. Fig. 9, no. 1 .

Shell. One elongated barrel-bead of Spondylus shell with biconical perforation. Length $1 \frac{5}{8}$ in.

Ochre. Six small lumps of earth heavily impregnated with red ochre.

Bone. The human bones are very fragmentary, but it can be said that they represent the skeletons of at least seven individuals. Of these two are those of young adults, while the rest belong to persons well advanced in years.

\section{Tomb No. 2}

Roughly circular in shape with an average diameter of $6 \mathrm{ft}$. and a depth of 6 in. Its north-eastern corner has been destroyed by a modern trench. A similar trench was dug up to the south-western edge of the tomb without, however, encroaching on the interior. Only small fragments of the paving stones survived. Fig. 2, no. 2.

The following objects were recovered from the burial layer:

(a) Pottery:

(1) Portion of a small, flat-bottomed dish decorated with incised lines radiating from a central dimple. Reconstructed. Ht. $1 \frac{5}{8}$ in., d. 4 in., base d. $1 \frac{1}{2}$ in. Fig. 5 , no. 1 , and P1. II, $b$, no. 1 .

(2) Fragment of the body of a small flat-based jar, similar to those from Tomb No. 1. Decorated with incised lines.

(3) Fragment of a very roughly made, shallow bowl. Undecorated.

The rest of the pottery from this tomb consists of small, badly-decayed sherds which give no clue as to the shapes of the vases to which they belong.

(b) Other finds:

Shell. One shell of Eobania vermiculata Mull. and one much decayed shell of Cypraea sp. Ocbre. Specimens of earth and decomposed soft rock impregnated with red ochre.

Bone. The human bones found are those of an adult, the sex not being determinable from the remains.

\section{Tomb No. 3}

Elliptical in shape, measuring $7 \mathrm{ft} .3$ in. in maximum length, $4 \mathrm{ft} .9$ in. in maximum breadth, and 5 in. in depth. Paving slabs were found but very much disintegrated. Orientation of major axis, NW. Fig. 2, no. 3 . 

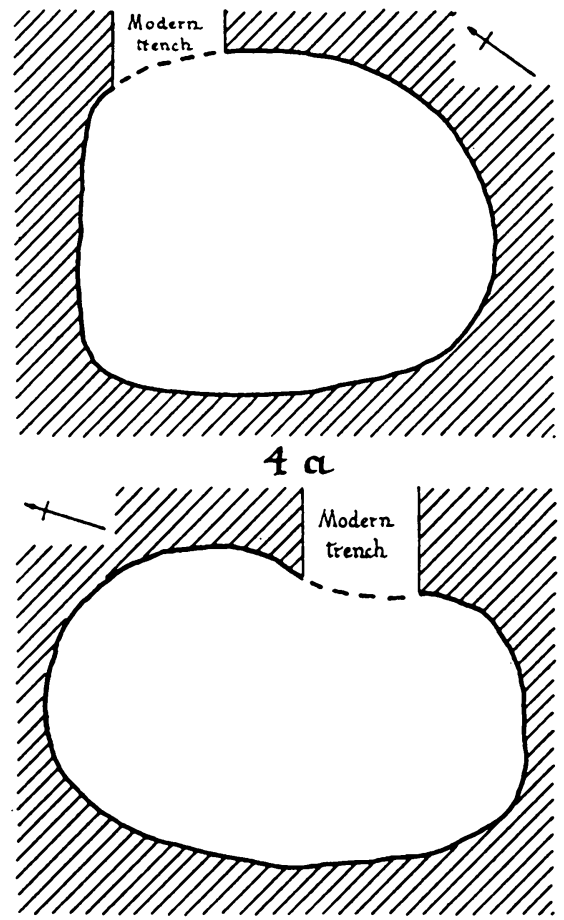

5 a

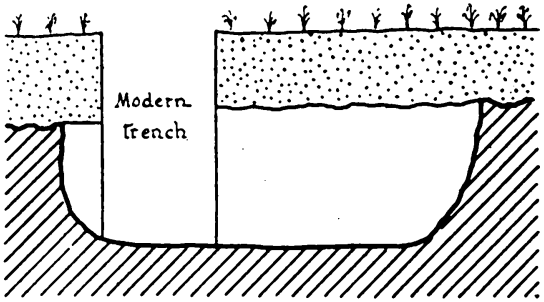

$4 \mathrm{~b}$

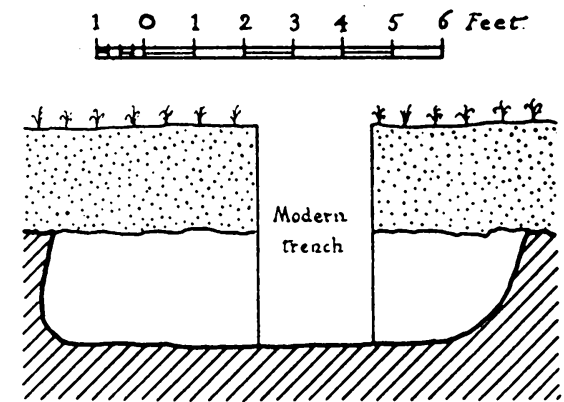

$5 \mathrm{~b}$

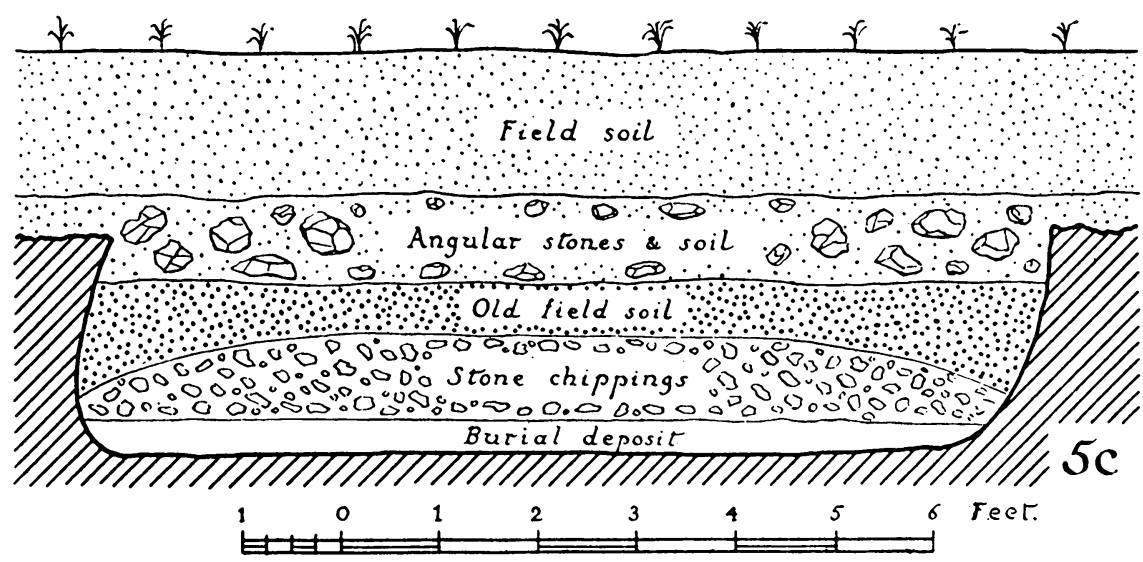

FIG. 3. 
The following objects were recovered from the burial layer:

(a) Pottery:

(1) Flat-bottomed dish with simple decoration of incised lines. The surface of the ware, where it survives, is well-polished, originally grey in colour but now deeply stained with red ochre. Reconstructed. Ht. $2 \frac{1}{2}$ in., d. $6 \frac{1}{8}$ in., base d. $2 \frac{1}{4}$ in. Fig. 5 , no. 2 , and Pl. II, $b$, no. 2.

(2) Horizontally-pierced lug, of the type used on bell-necked jars. All the rest of the pottery recovered was in small fragments. Some of these are portions of the rims or the flat bases of bell-necked jars, but the majority are too small to show anything of a profile.

(b) Other finds:

Stone. Portion of a bowl made from a piece of the local soft Globigerina Limestone. The exterior is very rough, though the base has been flattened to enable the vessel to stand firmly. The interior, on the other hand, has been hollowed out and finished with some care. Internal d. $4 \frac{3}{4}$ in.

Shell:

(1) Two shells of Cypraea sp., one having a deep groove at the anterior end of the aperture evidently to facilitate suspension. The second has a small hole at the same point, but it is not clear whether this is artificial or not.

(2) One elongated barrel-bead cut from Spondylus shell with biconical perforation. This object is in bad condition, the outer surface being much decayed, so that it is now almost shapeless.

Bone. The human remains are too few and fragmentary for determination.

\section{Tomb No. 4}

More or less oval in shape, but flattened on the NW. end, measuring $8 \mathrm{ft}$. 3 in. in maximum length, $6 \mathrm{ft} .9$ in. in maximum breadth, and $2 \mathrm{ft} .9$ in. in depth. A modern trench was excavated up to the NE. side of the tomb without, however, disturbing the burial deposit. As in the other tombs, very little remained of the original paving stones. Orientation of major axis NW. Fig. 3, no. 4 .

The following objects were recovered from the burial layer:

(a) Pottery:

(I) Portion of the body, with two horizontally-pierced lug-handles on the shoulder, of a large bell-necked jar. The upper part of the shoulder and the neck are missing. The ware is very much decayed with damp, but traces of an incised decoration are still visible. Partially reconstructed. Max. d. $7 \frac{1}{2}$ in. approx. Pl. II, $c$, no. $I$.

(2) Lower part of the body of a cup with omphalos base, like that from Tomb No. I. The place of attachment of a similar strap-handle is still visible, though the handle itself has been broken off. Traces of an incised decoration remain. The vessel has evidently at some time been filled with red ochre, and the whole interior 

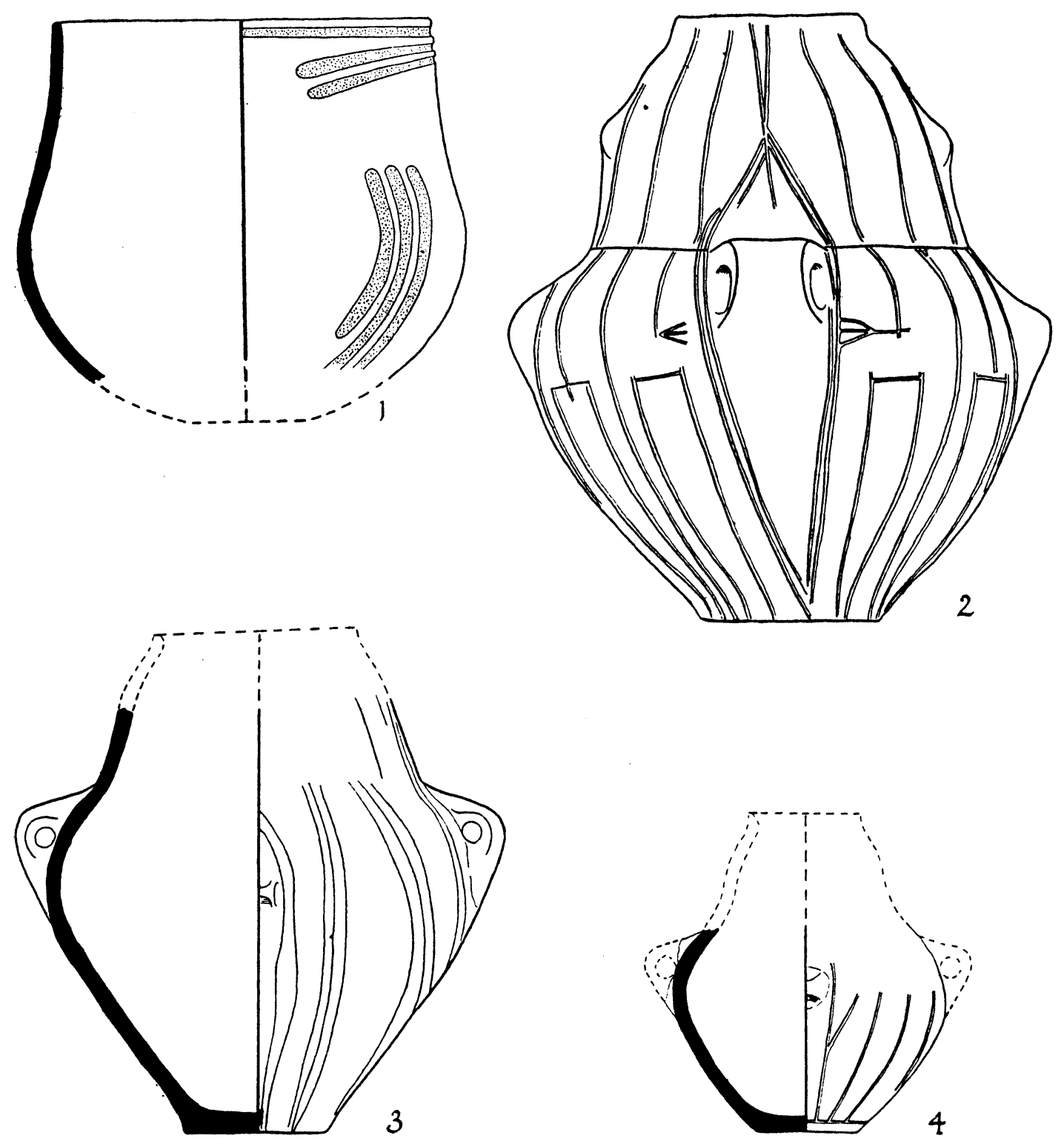

Fig. 4.-1. Tomb 1, No. 6. 2. Baldacchino Collection, Findspot Unknown (p. 18). 3. Томв 1, No. 2. 4. TOмB 1, No. 3. 
surface is still thickly encrusted with the remains of this. No measurements possible.

(3) Portion showing profile of a similar cup, with part of handle preserved. Mouth d. 3 in.

(4) Small jar, with depressed globular body and wide, flaring neck. On the shoulder two small, opposed, horizontally-pierced lugs and two knobs, each
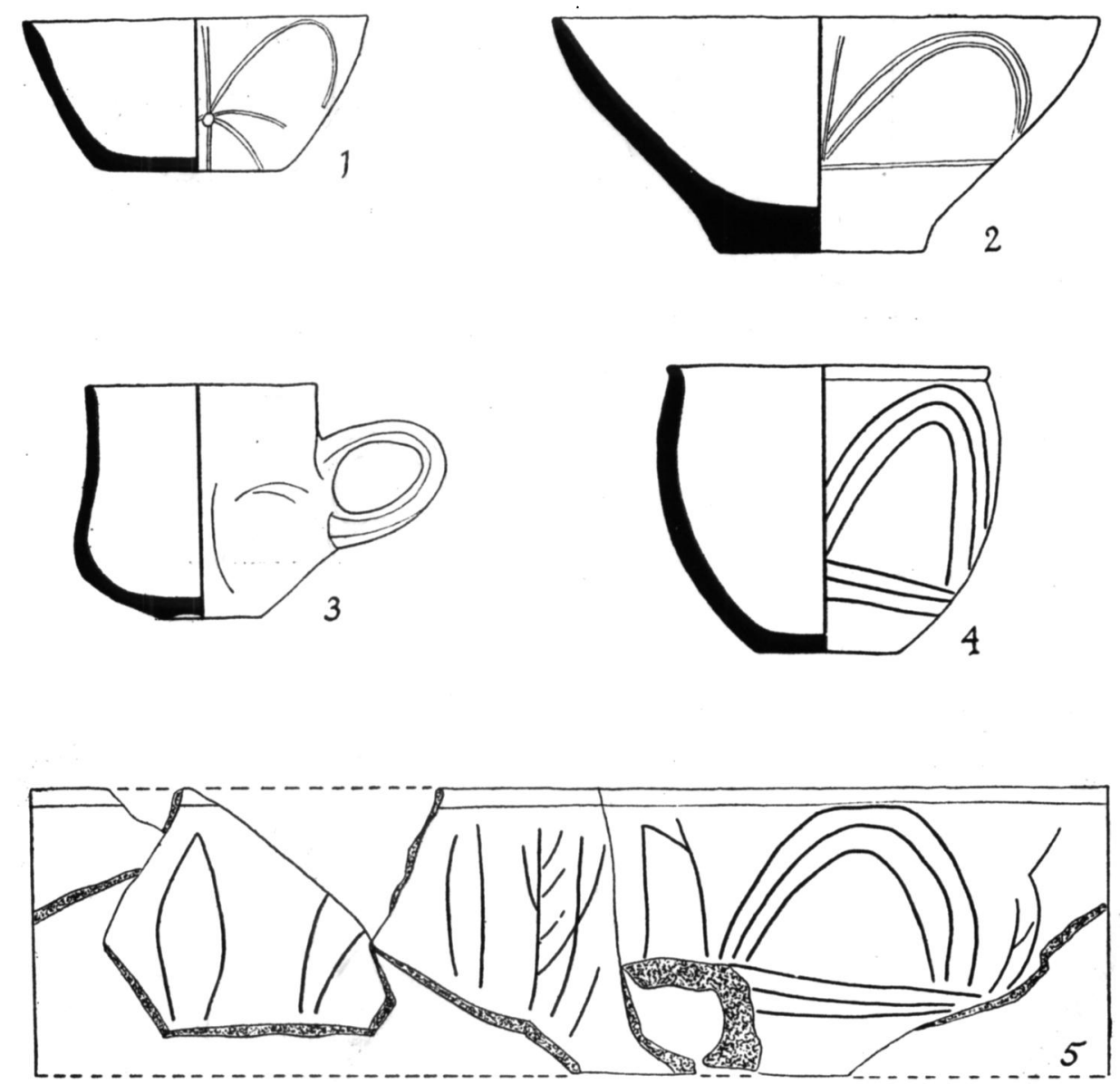

Fig. 5.-1. Tомв 2, No. 1. 2. Томв 3, No. 1. 3. Томв 1, No. 1. 4-5. TOMB 5, No. 2.

with a depression on either side to imitate the piercing of the lugs. Reconstructed. Mouth d. 2 in.

(5) Sherd of flat base, probably of a large bell-necked jar. Incised decoration. Base d. $2 \frac{3}{8}$ in.

(6) Three sherds of rims and one horizontally-pierced lug of bell-necked jars. Mouth d. $4 \frac{3}{4}, 3 \frac{1}{2}$, and 3 in. respectively.

(7) Six fragments of the necks and bodies of deep, necked bowls. Three of these 
show portions of a strap-handle which joins neck and shoulder. Five of the fragments comprise portions of the rim of the vessel. Decorated with incised lines. Mouth d. $7,9 \frac{1}{2}, 6 \frac{1}{4}, 8 \frac{3}{4}$, and $6 \frac{1}{4}$ in. respectively. Fig. 6, nos. $1-3$.
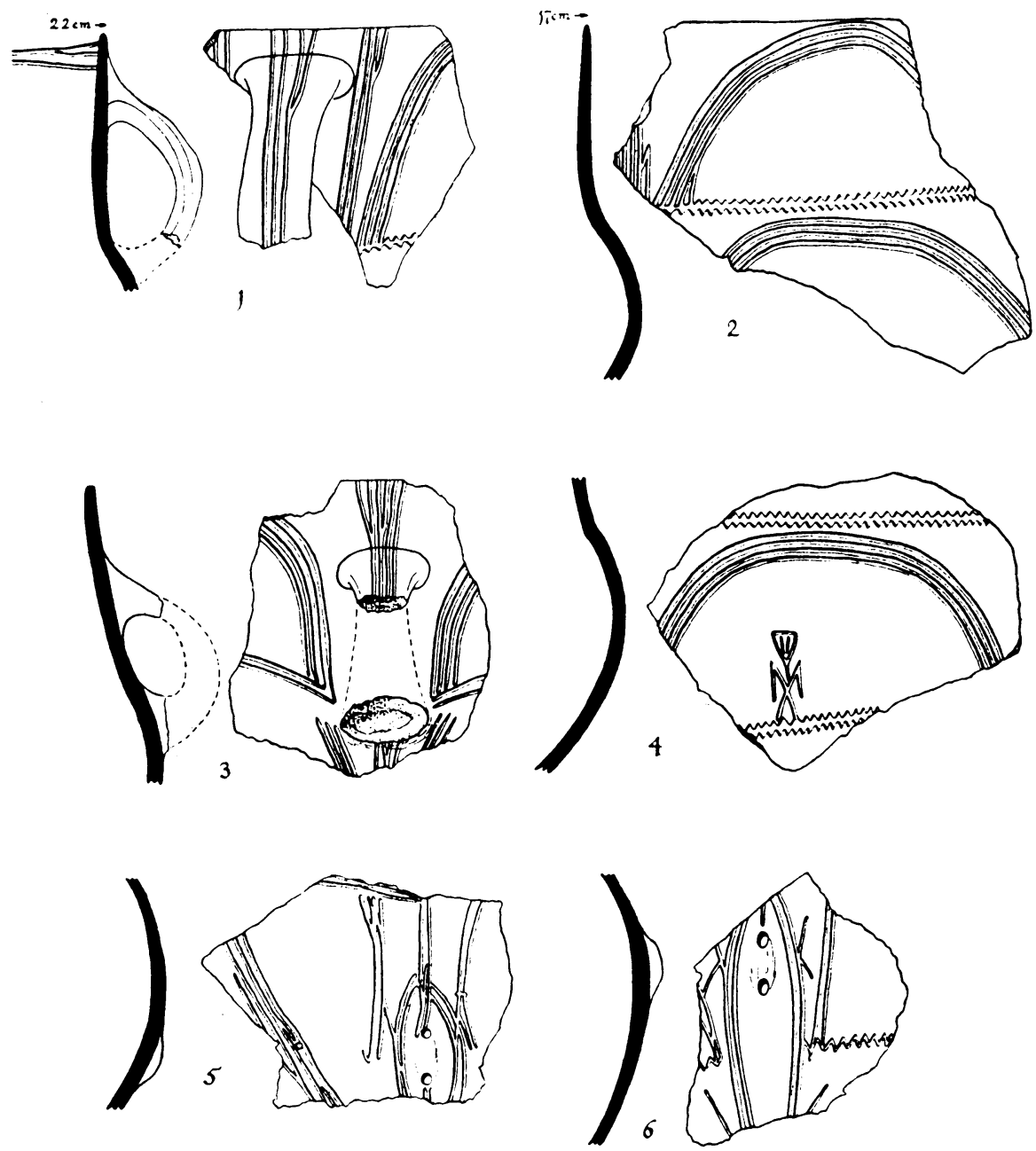

FIg. 6.-1-3. Tомв 4, No. 7. 4. Tомв 4, No. S. 5-6. Tомв 5, No. 5.

(8) Large fragment of the body of a large bowl, similar to those just described. The incised decoration is similar to that of the rest, except that it includes a small highly schematised human figure. Ht. $1 \frac{1}{4}$ in. Fig. 6, no. 4 .

(9) A much smaller fragment, perhaps of a similar bowl, incised with an almost identical though slightly smaller figure. The ware is very much decayed. Fig. 7, no. 10.

A large quantity of pottery was recovered from this tomb. So far as can be seen, it consists entirely of sherds of bowls and jars of the types described above. 
(b) Other finds:

Flint. Two small flint blades with trapezoidal section.

One is of dark brown translucent material with an extremely fine retouch along one edge only. The blade has been snapped off sharply at each end. Length $1 \frac{5}{8}$ in. Fig. 9, no. 4 .
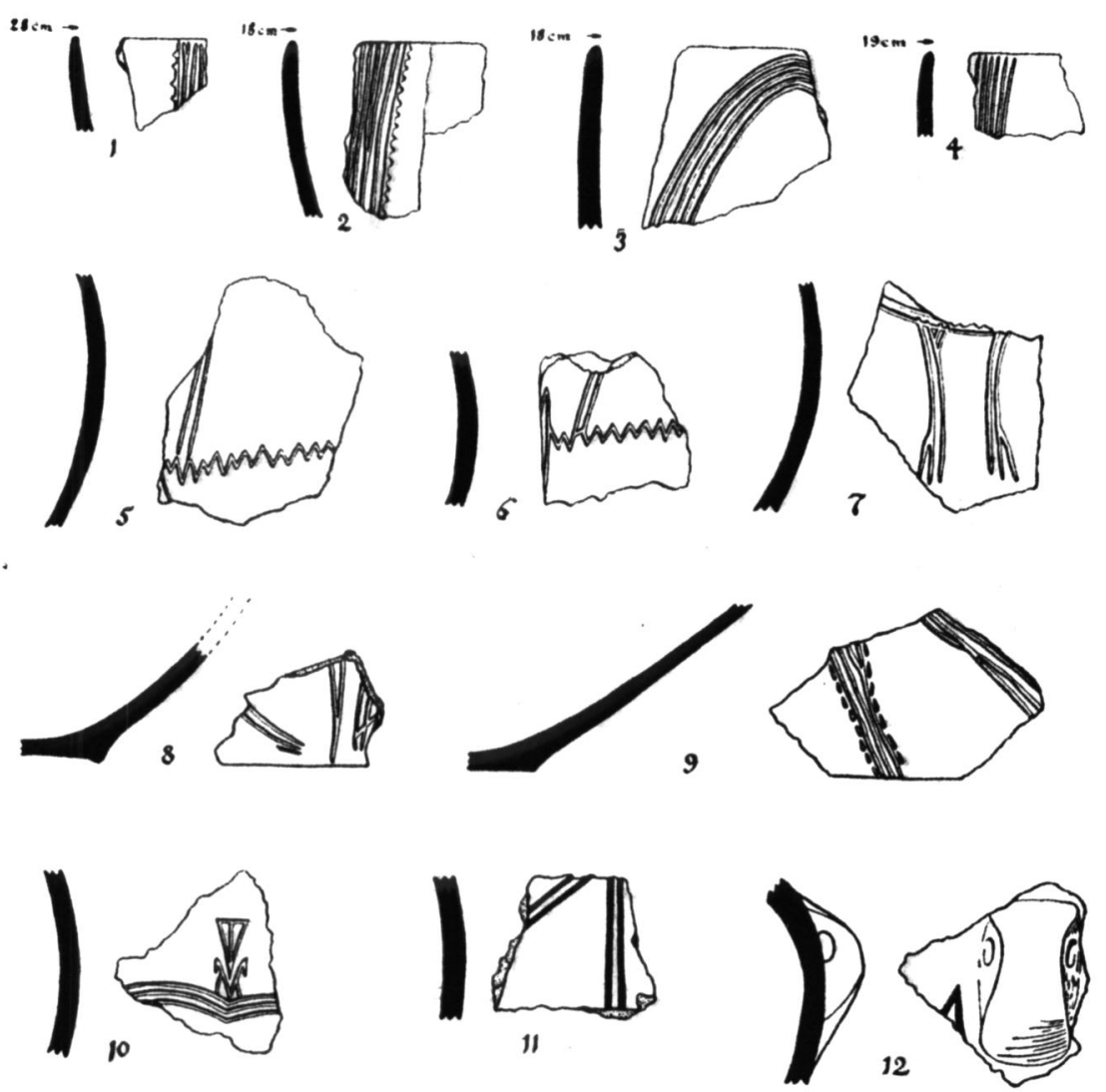

Fig. 7.-1-4. Томв 4. 5-6. Томв 5. 7. Томв 5, No. 8. 8-9. Томв 5, No. 4. 10. Томв 4, No. 9. 11-12. Томв 5, No. 9.

The other is of coarse-grained, greyish flint. The width of the blade narrows, and it curves over towards one end. Both edges are trimmed with a steep retouch. It is broken off at both ends. Length $1 \frac{5}{8}$ in. Fig. 9, no. 3.

Shell:

(1) Seven barrel-beads cut from Spondylus shell, varying in length from $\frac{1}{2}$ to 1 in. The shortest is also the broadest, having a diameter of $\frac{3}{8}$ in. All have a biconical perforation and are stained with red ochre. One in particular is thickly incrusted with this substance all over the exterior. Three of these are illustrated in Fig. 8, nos. $1-3$. 
(2) Seven shells of Dentalium rubescens Desh.

(3) One valve of Pectunculus glycimeris L., pierced at the umbo for suspension.

(4) Twenty-six shells of Eobania vermiculata Mull. Only a few are stained with red ochre.

(5) Thirteen shells of Rumina decollata L. None have traces of red ochre.

(6) Six shells of Helix aperta Born. No traces of red ochre.

Ocbre. Specimen of earth impregnated with red ochre.

Bone:

(1) Human remains of at least two adults were found, but on account of the condition of the bones it was not possible to determine the sex.
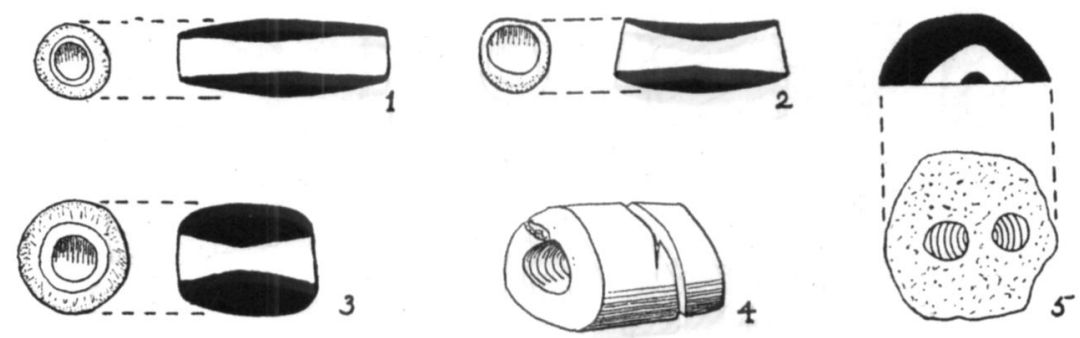

FI(i. 8. 1-i, TUMB + 4-5. TOMB 5.

(2) Remains of two goats or sheep. These bones, in contrast to the human ones and to the rest of the material from the tombs, show no traces of impregnation with red ochre, so that they may be of a later date and intrusive into the deposit.

Tomb No. 5

Kidney-shaped, measuring $9 \mathrm{ft} .8 \mathrm{in}$. in maximum length, from $5 \mathrm{ft} .4$ in. to $6 \mathrm{ft}$. in breadth and $2 \mathrm{ft} .3$ in. in depth. A modern trench was cut up to the east side of the tomb without extending into the interior. The paving stones were so much disintegrated that almost all traces of them had disappeared; their original presence was, however, established by a thin deposit of fine whitish earth lying below the burial deposit. Orientation of major axis, NNW. Fig. 3, no. 5 .

The following objects were recovered from the burial layer:

(a) Pottery:

(1) Portion of a vase, showing an inverted conical body, rounded shoulder, and broad flaring neck. The lower body and base are missing. Remains of an irregular but elaborate incised decoration can be seen. Conjecturally reconstructed. Max. d. $7 \frac{3}{4}$ in. approx. Mouth d. 7 in. approx. Pl. II, $c, 2$.

(2) Portion of a miniature pot with bead-rim, ovoid body, and small flat base. Decorated with a number of deeply incised lines, the scheme of which cannot be made out. Reconstructed. Ht. $1 \frac{1}{2}$ in. Mouth d. $1 \frac{3}{4}$ in. Fig. 5, nos. 4 and 5 . 

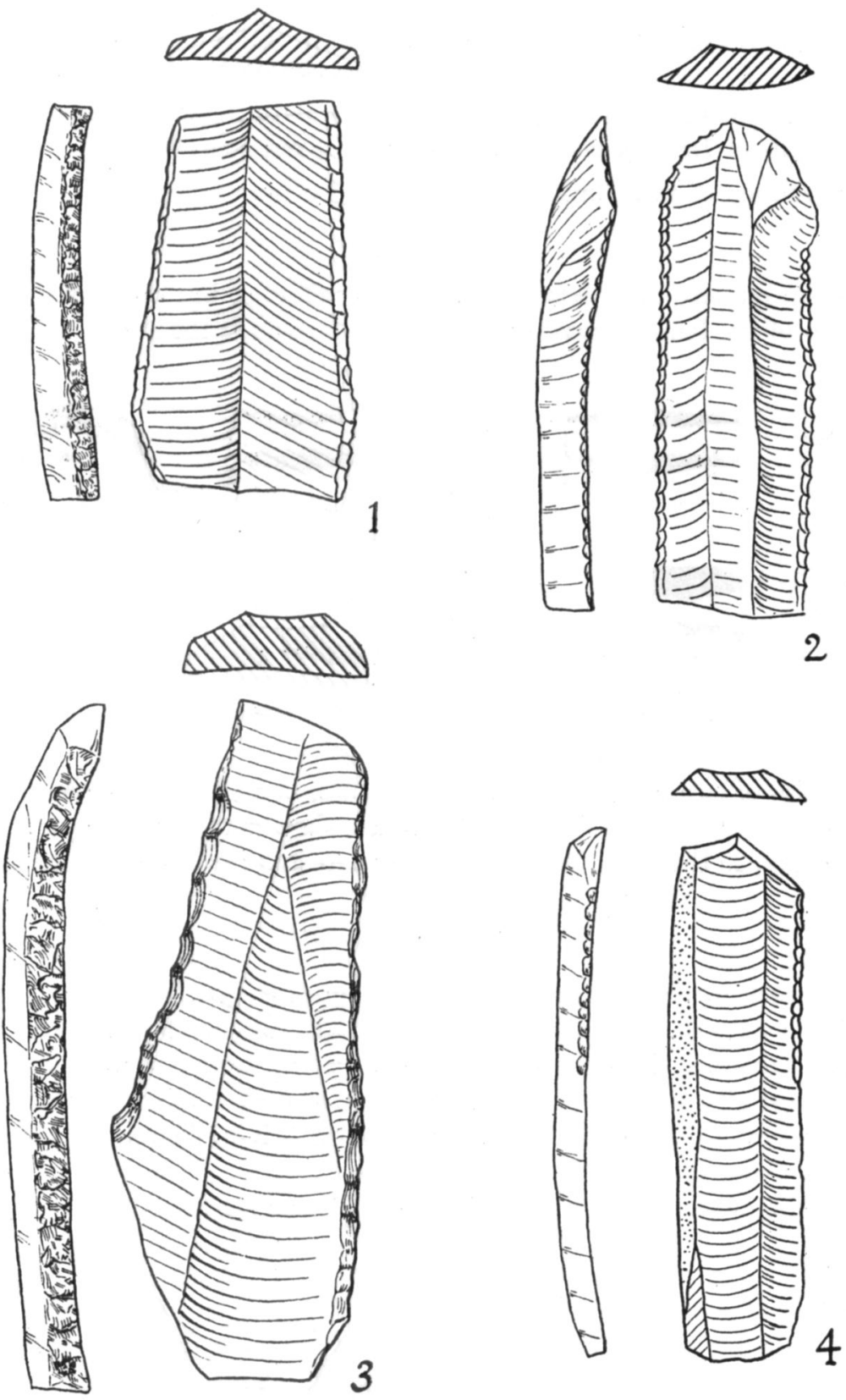

Fig. 9.-1. Томв 1. 2. ТОмв 5. 3-4. Томв 4 . 
(3) Five fragments of the rims of bell-necked jars with incised decoration. Mouth d. $4,3,3,2 \frac{3}{4}$, and $3 \frac{1}{2}$ in. respectively.

(4) Three fragments of the flat bases of jars. All have incised decoration, in one case bordered with lines of dots. Fig. 7 , nos. 8 and 9.

(5) Five large fragments of the bodies of bell-necked jars. Two have a horizontallypierced lug-handle. The remaining three have each a knob in which, in two cases, two circular depressions have been made, to imitate the appearance of a pierced lug. Fig. 6, nos. 5 and 6.

(6). Eight fragments of the rims and shoulders of necked bowls, all with the usual incised decoration. Mouth d. $9 \frac{1}{2}, 6 \frac{3}{4}, 7,7 \frac{1}{2}, 8 \frac{1}{2}, 7,8$, and 10 in. respectively.

(7) Two fragments of strap-handles, to one of which a fragment of the rim still adheres, showing it to have been attached to this. Both have incised decorations, and the second is notched along the edges.

(8) Sherd with an unusual incised decoration resembling two hanging arms ending in three-fingered hands. Fig. 7 , no. 7 .

(9) Four sherds of grey ware with a light buff surface, one of them with a horizontally-pierced lug-handle. All four are decorated with thin double lines of red paint. Fig. 7 , nos. 11 and 12.

There is a large mass of pottery from this tomb in the form of small sherds, belonging mostly to bell-necked jars and bowls of the type described.

Other finds:

Flint. One small blade of fine-grained grey flint with trapezoidal section, trimmed along both edges with an extremely fine retouch. It is broken off sharply at one end, while the other is carefully rounded. Length $1 \frac{1}{2}$ in. Fig. 9, no. 2.

Stone:

(1) Head of a statue-menhir made of the yellowish, compact variety of Lower Globigerina Limestone. It is damaged on the upper left-hand side, especially at the back, and shows an irregular break at the base where the rest of the block has been broken off. The edges of the block are rounded off and it is well finished on both sides. The face is in slight relief and outlined by a deep groove, and the same is true of the nose, which is the only prominent feature. Eyes and nostrils are indicated by pairs of small holes, and the mouth by a deeper conical drilling. Mouth and chin are connected by a vertical groove. The groove outlining the face is joined at the top by another, which runs horizontally round the sides and back of the head. A larger, vertical groove runs down the middle of the back. There is a slight trace of what appears to be the right shoulder where the stone is broken off below. The whole surface of the stone, especially the face, is stained with red ochre. These stains of red ochre also appear on the two scars, especially that of the main break, thus showing that this object was already broken when it entered the deposit. Max. ht. $7 \frac{3}{4}$ in., max. breadth 7 in., max. depth $3 \frac{1}{4}$ in. Pl. III.

(2) A fragment of Globigerina Limestone, evidently worked and representing part of a shallow vessel. The exterior wall is rounded and the base flattened some- 
what in the manner of a quern, the interior being hollowed into a shallow depression. Length 10 in., ht. $2 \frac{1}{\mathrm{in}}$.

(3) Small flattened pebble with well-rounded edges, but no traces of human workmanship. Max. d. $1 \frac{1}{2}$ in.

Sbell:

(1) Hemispherical button cut from Spondylus shell, with a V-shaped perforation on

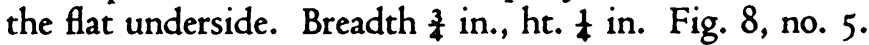

(2) Two valves of Dosinia exoleta L., each having a small hole pierced in the umbo for suspension.

(3) Two Cypraea shells, one broken and one nearly complete. The latter has a hole at the anterior end of the aperture deliberately made for the purpose of suspension.

(4) Twenty-three shells of Eobania vermiculata Mull., mostly stained with traces of red ochre.

(5) Five shells of Helicella Caruanae Kob., with no traces of ochre.

(6) Three shells of Helix aperta Born., one having slight traces of ochre.

(7) Five shells of Rumina decollata L., one only having traces of red ochre.

(8) One shell of Iberus Melitensis Fer., with traces of ochre.

(9) Three shells, one complete and two broken, of Cassis sulcosa Brug.; all are stained with red ochre, and one of the broken ones is full of it.

Ocbre. A number of large and small cakes of earth saturated with red ochre.

Bone:

(1) Very fragmentary human remains of a single individual. The person was an adult, but the sex could not be determined.

(2) Remains of a goat or sheep, and of an ox. Again it is possible that these are intrusive, since they are not stained with red ochre.

(3) Part of a long bone rubbed and polished for use as a bead, the medullary canal being used for suspension. It is divided into two segments by an incised line carefully cut at one point parallel to both ends. Length $\frac{3}{4}$ in., max. breadth $\frac{1}{2}$ in. Fig. 8 , no. 4 .

The homogeneity of the material found in each of them proves these graves to have all belonged to the same period. Since the pottery is clearly of the type distinguished by Mr. J. D. Evans as his Period $\mathrm{Ia}_{2}$, * the tombs as a whole may be assigned to this phase. Tomb 1, however, contained a pot (Fig. 4, no. 1) decorated with broad cut-out bands; this is characteristic of the preceding phase, and may indicate that this tomb was in use slightly earlier than the others.

From the invariable incompleteness of the pots recovered from these tombs it may be inferred that part of the burial deposits had been destroyed at some earlier date. This might have taken place when the area was first converted into an arable field. Further support for this idea may be gleaned from the extreme shallowness of Tombs Nos. 2 and 3 , and the great poverty of the material obtained from them. The tombs may all

* See p. 21, n. 17. 
originally have had the form of the well-tomb at Bukana excavated by Sir Temi Zammit in November, 1910, which contained some sherds of the Zebbug type. ${ }^{1}$

\section{Acknowledgements}

In conclusion, I wish to express my thanks to Mr. C. G. Zammit for his help in the field and for preparing the photographs and drawings with which this article is illustrated, and to Mr. J. D. Evans for his many helpful suggestions in the course of preparing it.

\section{J. G. BALDACChino}

\section{(ii) The Significance of the Finds}

The five prehistoric tombs described with their contents above constitute by far the most important group of early burials so far recorded in the Maltese islands. Tomb 5, as can easily be seen from the lists of finds, was the richest and most important, closely followed by Tombs 4 and 1. Very little was left of Tombs 2 and 3, and their yield was correspondingly poor.

It was immediately recognised that the pottery from these tombs differed entirely from that normally regarded as representing the earliest period of the islands' prehistory. Stronger still was the contrast with the types of ceramic current during the later prehistoric phases, from the Tarxien cremation-cemetery and the Borg in-Nadur and Bahria sites. The primitive appearance of the Zebbug pottery, which accorded well with that of the remainder of the tomb-furniture, suggested that here was an earlier stage of culture than anything hitherto recognised in the islands. New research on the prehistoric material from Malta and Gozo has substantially confirmed this surmise, and it can now be said with confidence that these tombs represent an earlier, more primitive phase of the culture well known from the finds in the Tarxien temples and at Hal Saflieni.

The pottery in the tombs was found in a very fragmentary condition; the small cup from Tomb I was the only vessel to emerge intact. Many of the sherds are small, and the ware is almost invariably much decayed, often to such an extent that it crumbles away in the hand. This decay is probably due to the continual seepage through the tombs of water from the field-soil above. The better-preserved pieces are seen to be made of a compact grey ware mixed with small white grits, which is covered with a fine, well-polished slip. The surface is generally somewhat mottled, and may vary in colour from light grey to almost black. The pieces are almost invariably decorated with lines deeply incised after the application of the slip.

The most common shapes found are two. The first is a jar with a singular bellshaped neck and inverted pear-shaped body (Fig. 4, nos. 3 and 4). On the shoulder are two opposed horizontally-pierced lug-handles, and between these are two smaller lugs or decorative knobs dimpled to imitate lugs. On the neck are generally two further small knobs standing directly above the first pair. It is a strange, but dignified and impressive form of vase, and examples occur in every tomb. The second type of vase is a deep, bagshaped bowl with a broad, only slightly constricted neck. A number of large sherds of 
such vases show that they were often fitted with at least one thin, broad strap-handle connecting the neck and shoulder (Fig. 6, nos. I and 3). Remains of these bowls were found in Tombs 1,4 , and 5 .

A less-common shape was the small, deep cup with omphalos base and large, oval strap-handle, of which a complete example was found in Tomb I (Fig. 5, no. 3, and Pl. II, a, no. I). Fragmentary remains of two similar ones were extracted from Tomb 4, making three examples in all. The flat-based dish with inverted conical body was also represented in two tombs, Nos. 2 and 3 (Fig. 5, nos. I and 2, and P1. II, b, nos. I and 2). From Tomb 5 came fragments of a tiny bead-rimmed pot with an ovoid body and flat base (Fig. 5 , nos. 4 and 5). Other shapes represented by one example only are a shallow, roughly-made bowl from Tomb 2, of which we have only one sherd, and a tall jar with flaring neck from Tomb 5. This latter is a somewhat conjectural reconstruction from a few fragments. It is evident that the range of forms is severely limited, and of those recognised only two are at all frequent.

With the exception of the bowl-fragment from Tomb 2, all the sherds of any size show traces of decoration. The motifs are generally rather elaborate, but only rarely are the fragments sufficiently large for the arrangement to be made out. The decoration is generally based on groups of from two to four parallel lines. The single line and groups of more than four are sometimes used, but they are not the norm. These groups of lines may be bordered by rows of dots (Fig. 7, no. 9), or, more frequently, by rows of small cut-out triangles with their bases resting on the outermost lines of the group (Fig. 7, nos. I and 2). On the necked bowls two rows of these triangles are sometimes cut baseto-base to accentuate the division between neck and body (Fig. 6, nos. I, 2, and 4). The necked bowl from Tomb I (Fig. 4, no. I) is unique in having a decoration of broad, shallow cut-out bands instead of the usual deep lines. The form of this bowl also looks somewhat more primitive than that of the other necked bowls.

Groups of verticals are often broken up by a curious motif like two flails laid across each other. When repeated several times it gives the verticals something of a 'Cornstalk' appearance. Another curious feature of the decorative style of the Zebbug pottery is the frequent occurrence of one or more irregular incised lines running round the interior of the mouths of vases just below the rim. The rims themselves are sometimes milled.

The following motifs are recognisable in the normal decoration: semicircles, with a tendency sometimes to take on a rather ogival form (Fig. 6, nos. 1-4, Fig. 7, no. 3), simple zig-zag lines (Fig. 6, no. 6, Fig. 7, nos. 5 and 6), horizontal bands formed by arcs of circles set end to end (Fig. 7 , no. 10), and blocks of vertical lines narrowing towards the lower end (Fig. 7, nos. 1, 2, and 4). Some fragments of jars are decorated with lines forming inverted isosceles triangles with the apex resting on the base of the vase. Besides these simple geometric motifs, however, there are numerous more complicated arrangements of lines which are not so easily described, and the significance of which will be discussed below.

A broad, but rather thin and fragile type of strap-handle is used on the cups and bowls (Fig. 5, no. 3, and Fig. 6, nos. I and 3), but far more common are various types of lugs and lug-handles. These are seen in their greatest variety on the jars, which have a number of different types on the neck and shoulders, viz. large horizontal lug-handles, smaller horizontally- or vertically-pierced knob-lugs, and finally unpierced knobs. The 
latter may be elongated either horizontally or vertically, and may or may not be decorated with dimples at either end to imitate the pierced lugs (Fig. 6, nos. 5 and 6).

Though some of these lugs have a distinct practical use, they also constitute an important decorative feature, since the more complicated incised patterns referred to above are built up around them. The lug-handles, with their slightly bevelled edges, seem to have suggested a pair of eyes, and the idea came of strengthening this by means of a crude arrangement of lines to suggest the rest of the figure. Only such a supposition can make this type of decoration intelligible to us. The feeling once aroused, it was carried over to the small knob-lugs, and even to the unpierced lugs, which are often provided with dimples to play their part more effectively. Finally, pairs of dimples may occur on a pot independently of the existence of a knob or lug, simply as a nodal point for decoration.

The anthropomorphic decoration is extremely abstract and schematised. Usually the head and body are indicated as fused together and almond-shaped, the outline being given by pairs of lines. Arms are indicated by pairs of lines or by single lines, and generally end in three-fingered 'hands'. Legs are never indicated (Fig. 4, no. 2, and Fig. 6, nos. 5 and 6). So far as can be seen, this type of decoration is confined to the jars. On two fragments of necked bowls, however, there appears a tiny human figure, schematised in an entirely different way. These have a triangular head and no body to speak of. Two crossed flails represent, in the one case arms and legs, in the other arms alone, the legs being added separately (Fig. 6, no. 4 and Fig. 7, no. 10).

The pottery of the Zebbug tombs is by no means such an isolated phenomenon as was at first thought. Wares of a similar type with similar, often identical, decoration, can be recognised among the material from almost all the temple-sites excavated. It is however, abundant only on sites such as Mgarr and Kordin I and III, where there are buildings of primitive form, having, that is to say, a trefoil or clover-leaf plan. In temples with a more developed plan, and in the large complexes where there is evidence of frequent rebuilding and extension, pottery of the Zebbug type is rare. The bulk of the ceramic material found in them is made up of the well-known wares with pitted, studded, scratched, or scale decoration. The Zebbug pottery would therefore seem to belong to an earlier and more primitive culture-complex than that characterised by the fine ceramics and exquisite spiral and animal designs in stone and paint found at Tarxien and $\mathrm{Hal}$ Saflieni.

There is, however, a noticeable difference between the pottery of Zebbug type from the temples and that from the tombs themselves, which is expressed both in the shapes and in the decoration. In the tombs the range of shapes is very restricted, and about three-quarters of the fragments seem to belong to bell-necked jars. In the temples, on the other hand, shapes are varied, and in particular various types of cups and shallow bowls are common. Bell-necked jars are comparatively rare, though ather types of jar are present. Corresponding to the rarity of the bell-necked jars is the rarity of the anthropomorphic decoration, though it is faintly adumbrated on a few vases.

This difference between the tomb and temple finds is emphasised by the existence in Malta, though mostly dispersed in private collections throughout the island, of a fine series of complete bell-necked jars. No information exists as to their finding, but their very completeness, with the fact that the surface is in every case stained and incrusted with red ochre, seems to indicate that they must have come from a tomb, or series of 
tombs, like the ones under discussion, but in all probability better preserved. One of the finest of these jars, from the collection of Dr. Baldacchino, is illustrated in Fig. 4, no. 2. This series of jars helped considerably in reconstructing the fragments from Zebbug, and also in understanding the general scheme of the decoration. From them it is clear, for instance, that there were two distinct types of decoration in use for the jars, one predominantly curvilinear, with much use of semicircles and ogival curves, the other (rather commoner) predominantly rectilinear, based on vertical lines and inverted triangles. It is with the latter decoration that the anthropomorphic elements are associated. The jar illustrated (Fig. 4, no. 2) is a good example of the rectilinear style, with the anthropomorphic features.

Parallels are not easy to find abroad for this peculiar and distinctive type of potterydecoration. However, it is possible to trace certain significant affinities between it and some of the post-Stentinello pottery of Sicily, which is grouped together under the general title of the San Cono-Piano Notaro culture. Among the features common to both are the general arrangement of the decoration, based on from two to four parallel lines, the border of dots, and the occurrence of wavy lines and of bands filled with rows of dots. Single dimples used as a nodal point for decoration are a feature of both wares (Fig. 5, no. I, and Pl. II, $b$, no. I).

The similarities extend to certain of the shapes also. The Zebbug tombs themselves, however, provide very little illustration of this, since the shapes are so limited, and the main one, the bell-necked jar, appears to be unknown outside Malta. However, the small ovoid jar with bead-rim from Tomb 5 (Fig. 5 , nos. 4 and 5 ) can be paralleled in the material from Piano Notaro, ${ }^{2}$ and the flat-bottomed dishes from Tombs 2 and 3 can also be paralleled among material from the same phase. Turning to the material of similar style from the Maltese temples, we find that the shallow bowls, particularly an example from Kordin III, can again be closely paralleled at Piano Notaro. ${ }^{3}$ A type of strap-handle with concave section, which is set on the rim of a cup of some sort, and which is common at Mgarr, ${ }^{4}$ has exact parallels from the Grotta Zubbia in Sicily. ${ }^{5}$ Finally, the shouldered bowl with a high strap-handle from Piano Notaro ${ }^{6}$ has an almost identical counterpart at Kordin III.

While it can scarcely be claimed that either of these cultures was the originator of the other, it may fairly be said that the affinities between them are such as to indicate contemporaneity and a certain amount of mutual influence. The origin of the postStentinello phase in Sicily remains obscure, though there appears to be some basic connection with the earlier phases. However, the decorative style shows much less cohesion and organic unity than that of the Zebbug type in Malta, and in particular the anthropomorphic elements are missing in Sicily. It seems possible, therefore, that the affinities may be due mainly to influence exerted from the Maltese side, but until a great deal more work has been carried out in both areas it would be unsafe to dogmatise on this point.

Before leaving the discussion of the pottery it will be necessary to say a few words

\footnotetext{
2 Orsi, Bull. Pal. It., xxxiv, 1908, pl. III, 5. Pl. III, I I however, is much closer to a form current in the later Tarxien phase (Period Ic).

${ }^{3}$ Ibid., pl. IV, 2 and p. 1 27, fig. B.

4 There is also one from Tomb 5 at Zebbug. See p. 13 (Tomb 5), No. 7 .
}

\footnotetext{
5 Orsi, Bull. Pal. It., xlviii, 1928, pp. 58-61. Unfortunately no illustrations of the material are included in this note on the exploration of the cave. The handles mentioned were seen in the Syracuse Museum.

${ }^{6}$ Orsi, Bull. Pal. It., xxxiv, r908, pl. III, 4.
} 
about the problem of Maltese red-on-buff painted pottery. The chronological position of this has been settled once for all by the finding in Tomb 5 at Zebbug of four small painted sherds (Fig. 7, nos. 11 and 12), identical in every way with those from the other sites. This painted pottery is not to be confused with the small quantity of painted ware found at the Hypogeum, Borg in-Nadur, and Bahria, which is much later and was probably made under Mycenean influence. It was found at Kordin III and Santa Verna, but the bulk of it comes from Mgarr. ${ }^{7}$ A careful study of the sherds of this early painted fabric shows that the motifs used conform closely to those incised on wares of the normal Zebbug type. Some fragments also possess lugs of the usual Zebbug types. Finally, at Mgarr there are numerous sherds of a light-faced ware, identical in shapes and decoration with the normal dark-faced Zebbug wares, though in colour and in the coarser quality of the paste and firing they compare with the painted ware. The significance of this small quantity of painted pottery escapes us at present, though it seems most likely that it is the product of a faint and belated influence of the Neolithic painted-ware cultures of South Italy on the Maltese islands.

The Zebbug tombs provide us with the only instance so far in Malta in which the non-ceramic aspects of a culture can be with certainty related to a particular type of pottery. Some of these non-pottery objects are themselves of great significance, and may lead us to important conclusions, especially when considered together with the pottery.

The remains of the stone and flint industries, with one notable exception, are not of great importance. There are two fragments of limestone vessels and four small flint blades. All of these are finely retouched to a greater or lesser extent, and one (Fig. 9, no. 2) is masterly in its workmanship. The smallness of the blades invites comparison with the flints from the San Cono tomb, but the working on the Maltese implements is finer, whereas arrow-heads, so numerous at San Cono, are completely absent. ${ }^{8}$

More important for comparisons are the shell beads and pendants, in particular a number of barrel-beads of Spondylus shell. Alone, these would be insufficient to warrant any conclusion, but from Tomb 5 comes a small domical button with $V$-perforation and an object which is evidently the head of a variety of statue-menhir (Pl. III). These two objects taken together, in conjunction with the anthropomorphic elements of the potterydecoration are, I think, sufficient to enable us to assign the Zebbug tombs to a definite phase in the wider development of Western Mediterranean prehistory. In this development the culture which they represent may have played a very significant role.

Buttons with $V$-perforation made of various substances, such as shell, bone, jet, amber, and even tin, make their appearance in Central and Western Europe at a definite moment, which coincides with the appearance of a number of other well-characterised elements, and generally with the first industrial use of copper. They are found in Danubian III in Central Europe, and in the Mediterranean in the Los Millares, Palmella, Remedello-Rinaldone, and Anghelu Ruju cultures. In South France they are associated with the spread of the complex assigned to Chalcolithic II. ${ }^{9}$ Pottery of Beaker type occurs in all the cultures mentioned, and V-perforated buttons are found

${ }^{7}$ Ashby, Excavations in Malta, 1908-11, figs. 6 and 25 , show the fragments from Kordin III and Santa Verna respectively. Zammit, Bulletin of the Valletta Museum, Vol. I, No. 1, p. 25, fig. 17, illustrates some specimens of painted wares from Mgarr.
${ }^{8}$ For the San Cono flint industry see Orsi, Bull. Pal. It., $\mathrm{xxv}, 1899, \mathrm{pl}$. V.

For this sequence see J. Hawkes, Arch. Journ., xcv, 1938, pp. 126-173 and V. G. Childe, Dawn of European Civilisation, 5th ed., 1950, pp. $293 \mathrm{ff}$. 
associated with beakers in other cultural contexts. Statue-menhirs seem to form a part of the same cultural horizon. In South France one is re-used as the lintel of a corbelled megalithic tomb. ${ }^{\mathbf{1 0}}$ Some North Italian examples are armed with a triangular midrib dagger clearly of Remedello type (an object specifically associated with V-perforated buttons at Monte Bradoni). ${ }^{11}$ In Spain and Portugal they belong to the complexes that produced the elaborately-decorated bone and schist idols, with which they have many features in common-that is to the complexes of Los Millares and Palmella and their equivalents.

The nature of the anthropomorphic decoration of the Zebbug pottery leaves no doubt of its connection with the weirder forms of megalithic art in the West. The 'expressionist' technique and phantasmagoric suggestion of the style often achieves a weird and uncanny effect, and its virtual limitation to the bell-necked jars makes one suspect a specifically funerary intention. The two curious schematised figures on fragments of necked bowls (Fig. 6, no. 4, and Fig. 7, no. 10) are in a somewhat different style, but even this is distinctly reminiscent of the figures in some of the metal-age rockpaintings of Spain and South France.

The Zebbug statue-menhir is unfortunately broken off at the neck, so that the evidence of whatever arms or ornaments may have been carved on the lower part is lost to us. However, it is perhaps worth noting in passing that some of the French statuemenhirs have necklaces, the principal feature of which is a large barrel bead in the centre, similar in shape to the shell ones from Zebbug. The carving of the face of the Zebbug statue-menhir differs in a number of ways from that of the Spanish, French, and Italian ones. One fundamental point is that it is carved in slight relief instead of being cut back into the stone in the manner of the majority of the Western examples. ${ }^{12}$ A more significant difference, however, is the indication of the mouth by a conical drill-hole, with a vertical groove joining it to the base of the chin. On the Western statue-menhirs the mouth is normally not indicated at all; the method of indicating it by a dot and line is well known on the pottery plank-idols of Cyprus, though in their case the line generally runs upward to join the nose. These plank-idols are themselves very closely paralleled by the flat schist idols of South-western Spain and Portugal..$^{13}$ Perhaps it would not be too rash to suggest that we have here in Malta a link in the chain of connection, one which may be further elucidated by future discoveries.

There remains to be considered what may be gleaned from the form of the tombs about the external relations of the Zebbug culture. Only two tombs of the San Cono culture are known in Sicily, that of San Cono itself and one other. It is noteworthy, however, that when found these presented the same aspect as those of Zebbug-namely a more or less circular hollow scooped out of the soft rock. It has already been remarked in Part I that the curious form of the Zebbug tombs might well be due to the destruction of the rock in which the upper part of the tomb was worked. This might also have been the case with the Sicilian examples, which were in any case further mutilated by their chance finders. ${ }^{14}$ The original form might have been either a chamber tomb or a welltomb. In Malta scanty remains of pottery of the Zebbug type were found mixed with

\footnotetext{
${ }^{10}$ Childe, op. cit., p. $30 \mathrm{r}$.

11 Colini, Bull. Pal. It., xxv, 1899, p. 301.

12 Observation made by Dr. R. Battaglia in a letter to Dr. Baldacchino.
}

\footnotetext{
13 Already remarked on by B. Saez Martin in Actas $y$ Memorias de la Soc. Esp. de A. E. P., 1944, pp. 134 ff. 14 Orsi, op. cit., p. 56.
} 
later pottery in a well-shaped tomb at Buqana, Attard, in 1910,15 but pottery of the immediately succeeding phase has occasionally been found in simple chamber tombs. ${ }^{16}$

To sum up the significance of the Zebbug tombs, we may say that the pottery from them seems to fit into the sequence of Maltese ceramics between the last pottery of Stentinello tradition and the first of the wares with scratched and red-incrusted decoration, which culminate in the series from Tarxien, Saflieni, etc. ${ }^{17}$ It shows marked similarities to the material of the San Cono phase in Sicily, with which it can be considered to be contemporary. Certain features of the pottery-decoration, and some of the nonceramic finds, enable us to find analogies farther afield and to relate the culture to those of Palmella, Los Millares I, Chalcolithic II of South France, Remedello, early Anghelu Ruju, and so to the earliest phase of the Beaker expansion in the West Mediterranean. If we may take it that all these cultures were in progress by about the middle of the nineteenth century B.C., then it seems likely that the Zebbug culture must also have been flourishing at about that time. Furthermore, if we allow that certain features, such as the $\mathrm{V}$-perforated buttons, triangular midrib daggers, and statue-menhirs, are ultimately of East Mediterranean derivation, we may propose a date slightly earlier than that of any of these for the inception of the Zebbug phase in the Maltese islands.

J. D. Evans

15 Zammit, Ant. Journ., viii, 1928, pl. LXXVI, fig. I. ${ }^{16}$ E.g., Nadur (Zammit, op. cit., p. 482); probably also Busbizija (Valletta Museum Annual Report, 1928-9, p. IV), but this was damaged. The North Cave at Ggantija (ibid., 1949-50) seems to have been a crudely cut chamber tomb. This was used as a dump for pottery from the neighbouring temple, but a few fragments of Zebbug ware may represent the remains of the original burial.

17 For the Maltese pottery-sequence referred to above see J. D. Evans, 'The Prehistoric Culture-Sequence in the Maltese Archipelago,' Proceedings of the Prehistoric Society, xix, pt. I, pp. 41-94. Thanks are due to the Prehistoric Society for loan of the blocks for figs. 5 and 6 of the present article. 

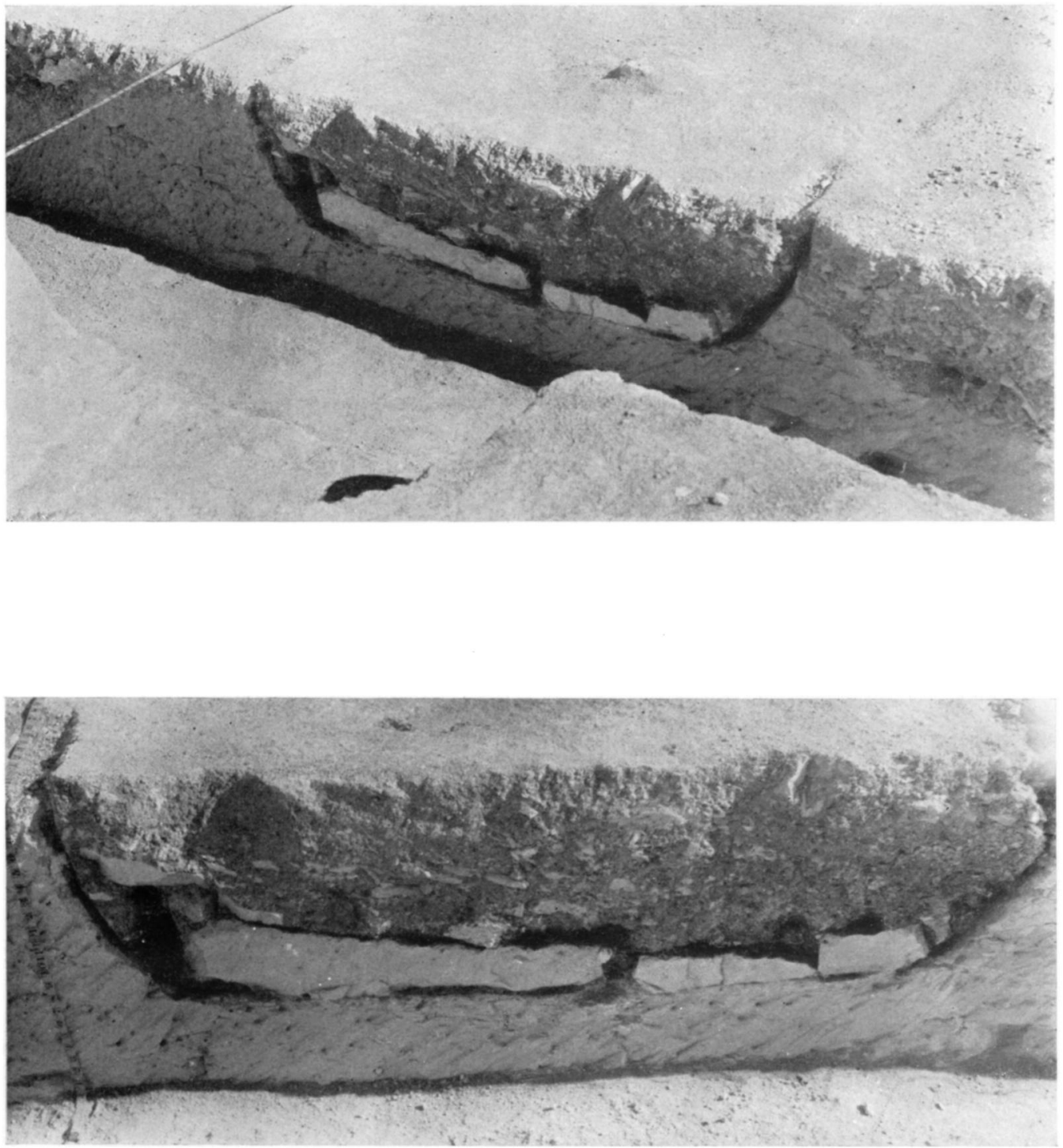

Zebbug, Malta, Tomb i (p. I)

(Photos: Valletta Museum) 
PLATE II

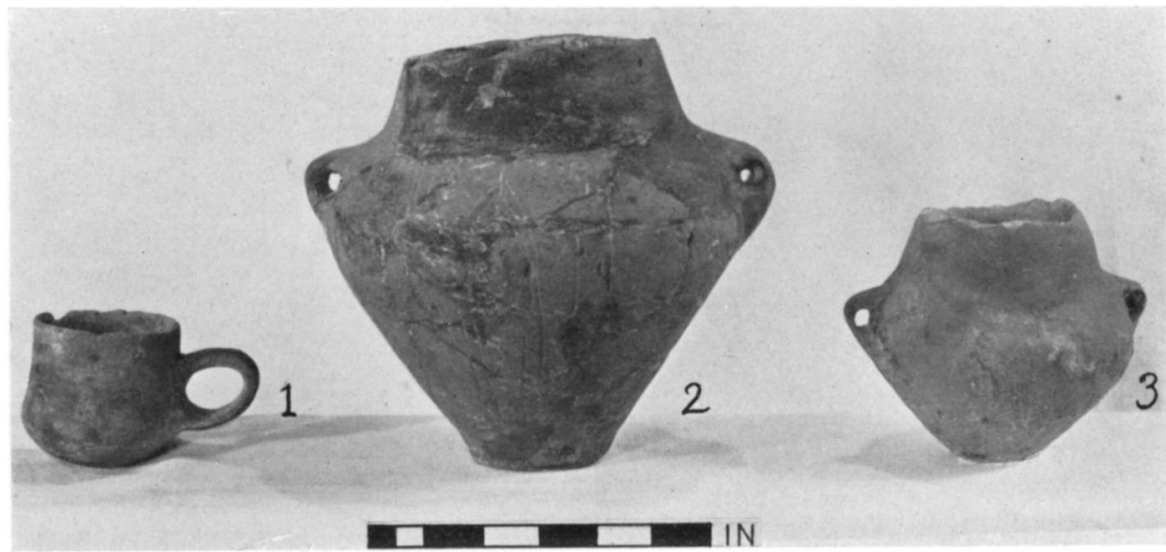

a. ТомB

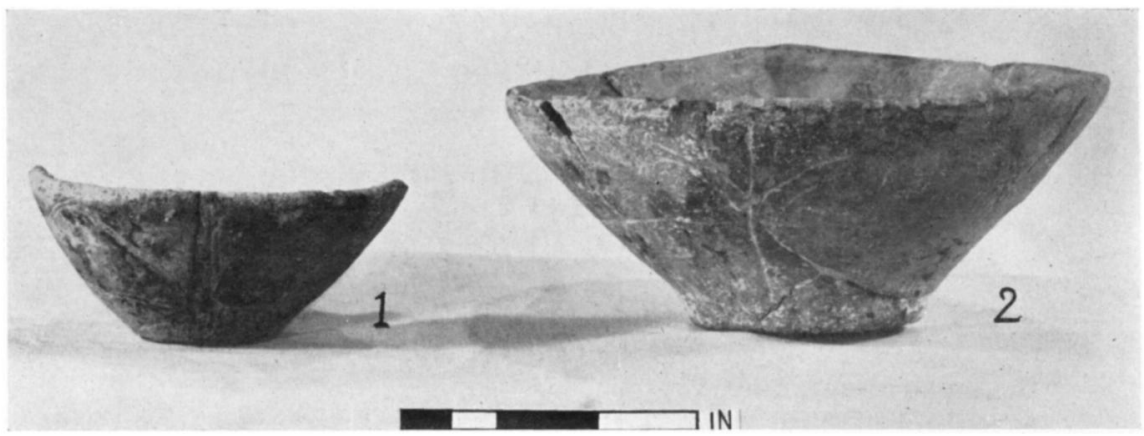

l. І, ТОМВ 2; 2, ТОМВ;

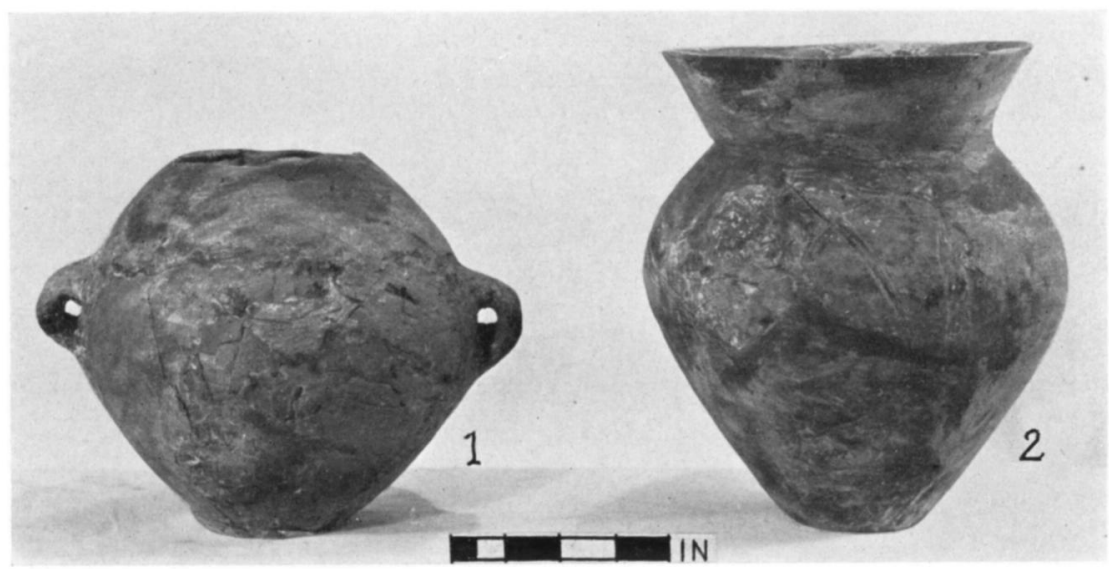

c. I, TOMB 4: 2, ТOMB 5

Prihistoric Potterl irom Zibbug, Malita pp. 2, f, 6, 11 (Valletta Muse'um) 

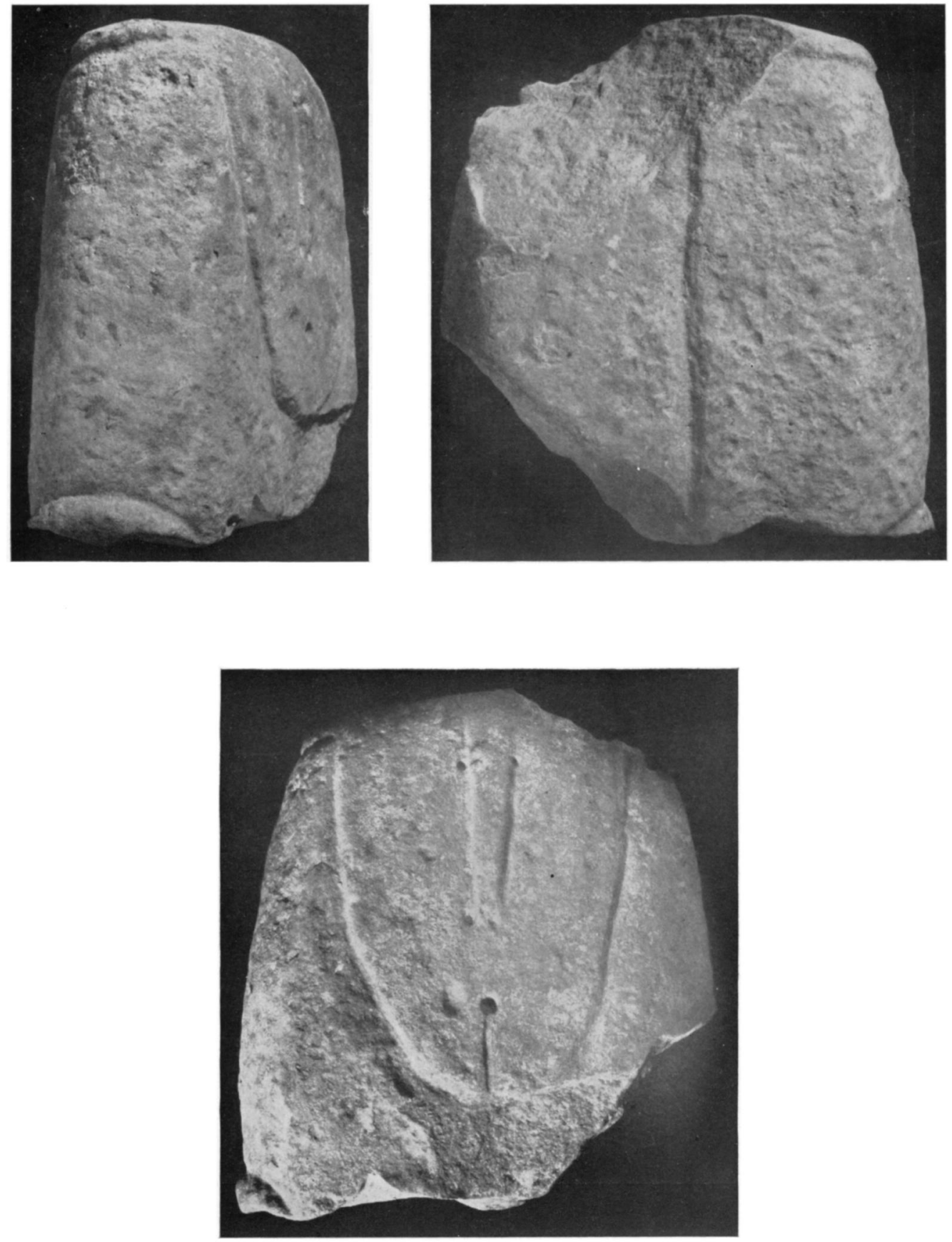

Zfbbu(i, Malta: Head of Statue-menhir (pp. 13,20 ) (Valletta Museum) 